Dhaka Univ. J. Bol. Sci. 27(2): 125-134, 2018 (July)

\title{
LIFE CYCLE, FEEDING BEHAVIOR AND NATURE OF DAMAGE OF SWEET POTATO LEAF MOTH, AGRIUS CINGULATA (FABRICIUS) AND AGRIUS CONVOLVULI (LINNAEUS) (LEPIDOPTERA: SPHINGIDAE)
}

\author{
Bani Halder, Shanjida Sultana, Tangin Akter and Shefali Begum* \\ Department of Zoology, University of Dhaka, Dhaka-1000, Bangladesh
}

Key words: Agrius cingulata, Agrius convolvuli, Sweet potato, Life cycle, Feeding behavior

\begin{abstract}
The sweet potato hornworm Agrius cingulata and Agrius convolvuli are destructive pests of sweet potato. This study was conducted to observe the life cycle and the feeding potential of larval instars of A. cingulata and A. convolvuli under laboratory condition $\left(28 \pm 4^{\circ} \mathrm{C}, 70 \pm 4 \% \mathrm{RH}\right.$ and $12 \mathrm{~L}: 12 \mathrm{D}$ photoperiod). The laboratory study revealed an average incubation period of $6 \pm 0.50$ days for A. cingulata and $4 \pm 0.50$ days for $A$. convolvuli, larval duration of $42 \pm 1$ days for $A$. cingulata and $24 \pm 1$ days for $A$. convolvuli, pupation period $26 \pm 1$ days for $A$. cingulata and $14 \pm 1$ days for $A$. convolvuli. The life span from egg to adult stage, on an average, was 73 days for $A$. cingulata and 55 days for $A$. convolvuli. The larval feeding potential was determined by both the maturity and availability of suitable leaves although mature larvae were observed to feed on the stems and flower of the host plant in absence of suitable leaves. The larvae of both hornworms preferred mostly the young and mature leaves. The caterpillars of $A$. cingulata and A. convolvuli were found voracious feeder. The nature of damage of sweet potato hornworm mostly occurred on the host-plant. The yield of sweet potato was reduced due to the infestation of the pests.
\end{abstract}

\section{Introduction}

Sweet potato is an important vegetable crop in tropics, sub-tropics and temperate regions. It is considered the sixth important crop in the world, after wheat, rice, corn, potato and barley(1). It is normally cultivated as an annual crop. About $44 \%$ of the sweet potato growers of Bangladesh grow sweet potatoes in less than 0.1 hectare of land; and only $8 \%$ of the growers allot more than 1.0 hectare of land to produce sweet potatoes ${ }^{(2)}$. The production and productivity of the crop is affected by many constraints ${ }^{(3)}$. Among the major biotic constraints, insect pests cause major losses to sweet potato production in developing countries(4-5). Over 300 species of insects and mites infest sweet potato throughout the world ${ }^{(6)}$. Among them, Agrius cingulata, the pink-spotted hawk moth, and Agrius convolvuli, the Convolvulus hornworm are the major ones. Both species feed as caterpillars especially on the plants of Convolvulaceae family and typically inhabit tropical and subtropical environments ${ }^{(7)}$.

*Author for correspondence: <shefali@du.ac.bd>. 
The hornworm causes damage in two principle ways. Mechanical way by defoliate the leaves of sweet potato plant and by transmitting viral disease. One large larva of Agrius cingulata or Agrius convolvuli can defoliate a plant on its own, and a large population of older larvae can defoliate a field completely overnight ${ }^{(8)}$. The yield losses of sweet potato can occur if heavy defoliation takes place by Agrius cingulata and Agrius convolvuli when the crop is young ${ }^{(9)}$. Because heavy infestations by hornworm cause the crop withered and death.

Infestation with smaller population during early stage of plant growth reduced the number of tillers, plant height and the general vigor, but after penicle initiation similar population greatly increases the percentages of unfiled crops ${ }^{(10)}$.

This study has been designed to enable the losses from insect attack to be minimized by proper identification of the pest and the application of proven control measures. The objectives of the study were to observe the life cycle of Agrius cingulata and Agrius convolvuli, and at the same time to observe their feeding behavior and nature of damage.

\section{Materials and Methods}

The study was conducted from 26th February, 2011 to March, 2012 at Bongar Chor, Narsingdi $\left(23^{\circ} 48^{\prime} 0^{\prime \prime}\right.$ N, 9045'0" E; Fig. 1), Modhukhali, Faridpur $\left(23^{\circ} 32^{\prime} 5^{\prime \prime}\right.$ N, 89 $37^{\circ} 8^{\prime \prime}$ E;

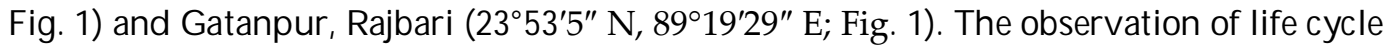
and feeding behavior of pink-spotted hawk moth on sweet potato was started on 27th February, 2011. Behaviors were observed in the selected stations through the period.

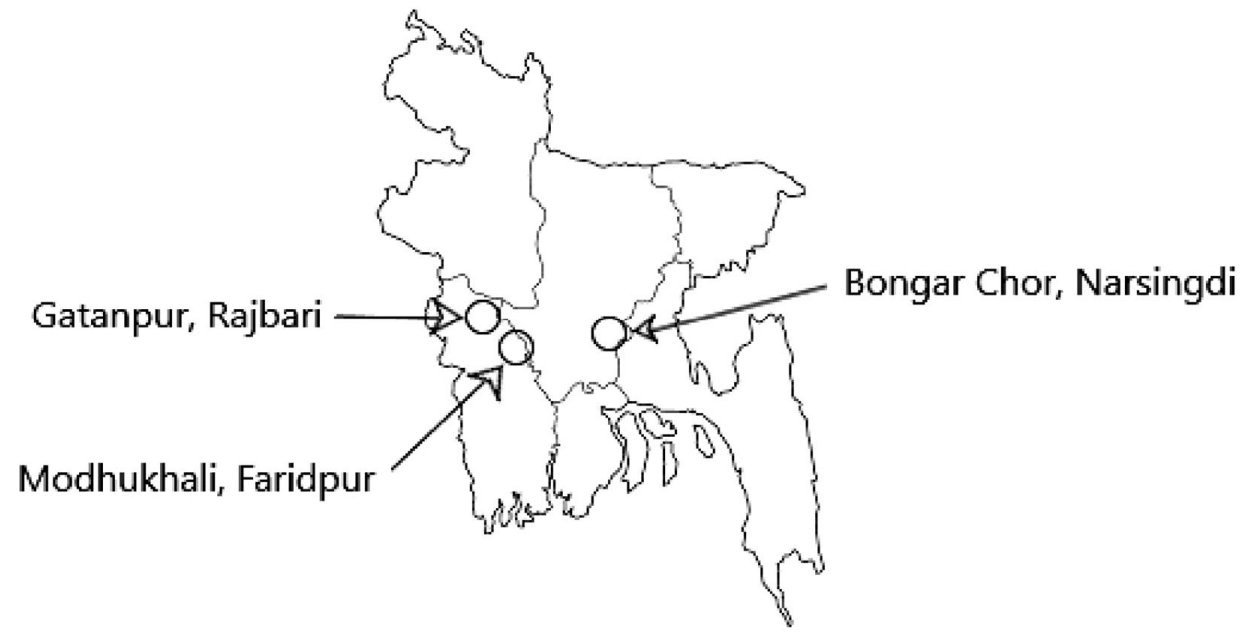

Fig. 1. Study sites.

After observation experiment was started in February, 2011 and experiments were carried out in the Entomology Laboratory $\left(28 \pm 4^{\circ} \mathrm{C}, 70 \pm 4 \% \mathrm{RH}\right.$ and $12 \mathrm{~L}: 12 \mathrm{D}$ photoperiod), Department of Zoology, University of Dhaka. 
The infested sweet potato plants with the larvae of pink-spotted hawk moth were collected from the study sites in natural condition. The infested sweet potato plants were kept in an insect culture bucket (height $29 \mathrm{~cm}$; diameter) covered with a piece of net. Some pink-spotted hawk moths were emerged within 8 to 10 weeks. Fresh sweet potato plants were supplied for continuous rearing and the newly emerged adults were used for the experiment. The adults were identified according to Hodges ${ }^{(11)}$.

Forty nine samples were selected from the newly emerged adults and among them 13 individuals were Agrius cingulata and the other 36 individuals were Agrius convolvuli. The length, width and weight of the larvae were measured in the laboratory. The adults were placed in two different buckets, which were covered with a piece of net, tied up with rope and experiments were carried out at room temperature $\left(28 \pm 4^{\circ} \mathrm{C}\right)$ and humidity $(70$ $\pm 4 \%$ ). The incubation, larval, pupal, and the adult periods were recorded regularly for two successive generations. Total life cycle of sweet potato hornworm was recorded from the first day of egg laying to the adult death.

Experimental data for observing feeding behavior were counted periodically. The percentage of large irregular holes in the leaf blades, which caused by them and the number of leaves fed by them, was counted. Experimental data were counted at the morning, afternoon, evening and night. Feeding sites, mode of feeding, duration of feeding and preference of the leaves were noted. Daily observation was carried out for the determination of the infestation rate of sweet potato leaves. The total loss of the sweet potato leaves was recorded after the end of the sweet potato hornworm life cycle. In this experiment 49 larvae were used just after their hatching. The size of the sweet potato of infested sweet potato plant and non-infested one was observed. To observe the effect of feeding on the size of the sweet potato between the infested and non-infested plant, two sweet potato plants were planted into two separate tubs where 50 tuber worm moths were introduced into one tub and other tub was rapped by mosquito net so that no infestation could occur.

\section{Results and Discussion}

A complete metamorphosis had been seen in the life cycle of both Agrius cingulata and Agrius convolvuli which encompassed four stages including egg, larva, pupa and adult. The description of these stages is given below.

Egg: The eggs were deposited singly on the underside of the foliage. They were nearly round or spherical in shape, but flattened at the bottom surface. The color of the eggs was mainly whitish or greenish or yellowish. Each egg measures about $1.35 \mathrm{~mm}$ in diameter. The incubation period was 6 - 10 days for Agrius cingulata and 4- 6 days for Agrius convolvuli (Fig. 2).

Larva: The freshly emerged larvae were transparent pale green in color. The first instar larva turned into pointed blackish in color with orange markings (Fig. 3). But, the 
average duration of 1st instar larva was seven days for Agrius cingulata and six days for Agrius convolvuli (Fig. 2).

Second instar caterpillars were greenish, covering with minute whitish bristles on both dorsal and lateral sides. The pointed black marks became prominent in Agrius convolvuli, (Fig. 3), but in Agrius cingulata rounded orange markings on the body became larger and conspicuous (Fig. 4). Second instars ranged from six to eight days with an average of $8 \pm 0.50$ days for Agrius cingulate and five days with an average of $5 \pm 0.50$ days for Agrius convolvuli (Fig. 2).

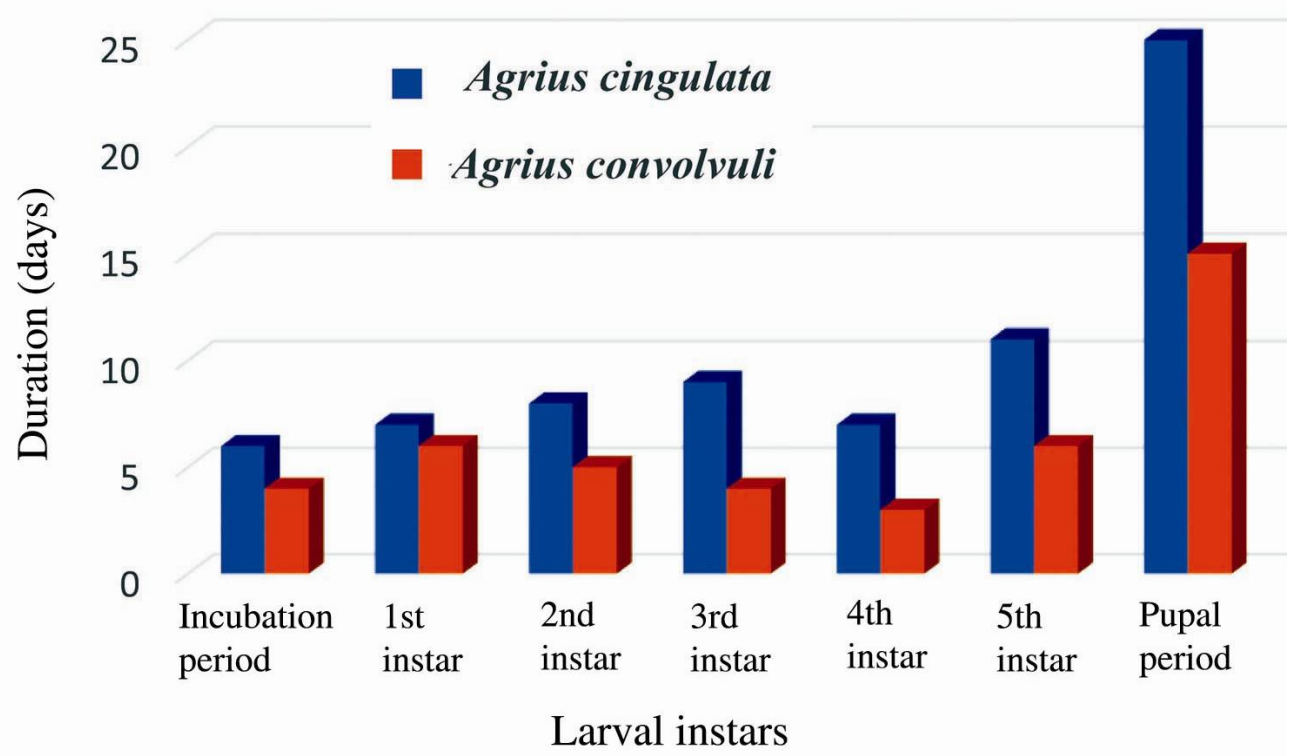

Fig. 2. Showing the comparisons of the duration of incubation period, different larval instars and pupal period between Agrius cingulata and Agrius convolvuli.

The body of third instars became green or light yellowish green and the minute whitish bristles on both dorsal and lateral sides became prominent. The whitish patch was also become conspicuous and covered the whole body of Agrius cingulate (Fig. 3), but in Agrius convolvuli the whitish patch was not prominent; the pointed black marks became more deep and larger and rounded (Fig. 4). The 3rd instar larval duration varied from 8 to10 days for Agrius cingulata and for Agrius convolvuli it was 5 days (Fig. 2).

At the stage of 4th instar the two species of hawk moth looked totally different from one another. The whitish patch became most conspicuous, wide and covered the whole body of $A$. cingulata, rounded orange markings on the body became larger and finally became dark-brownish (Fig. 3). In A. convolvuli the blackish and whitish patch became prominent; the pointed black marks became more deep and larger and rounded (Fig. 4). 
Fourth instars ranged from six to eight days for $A$. cingulata and four days for $A$. convolvuli (Fig. 2).

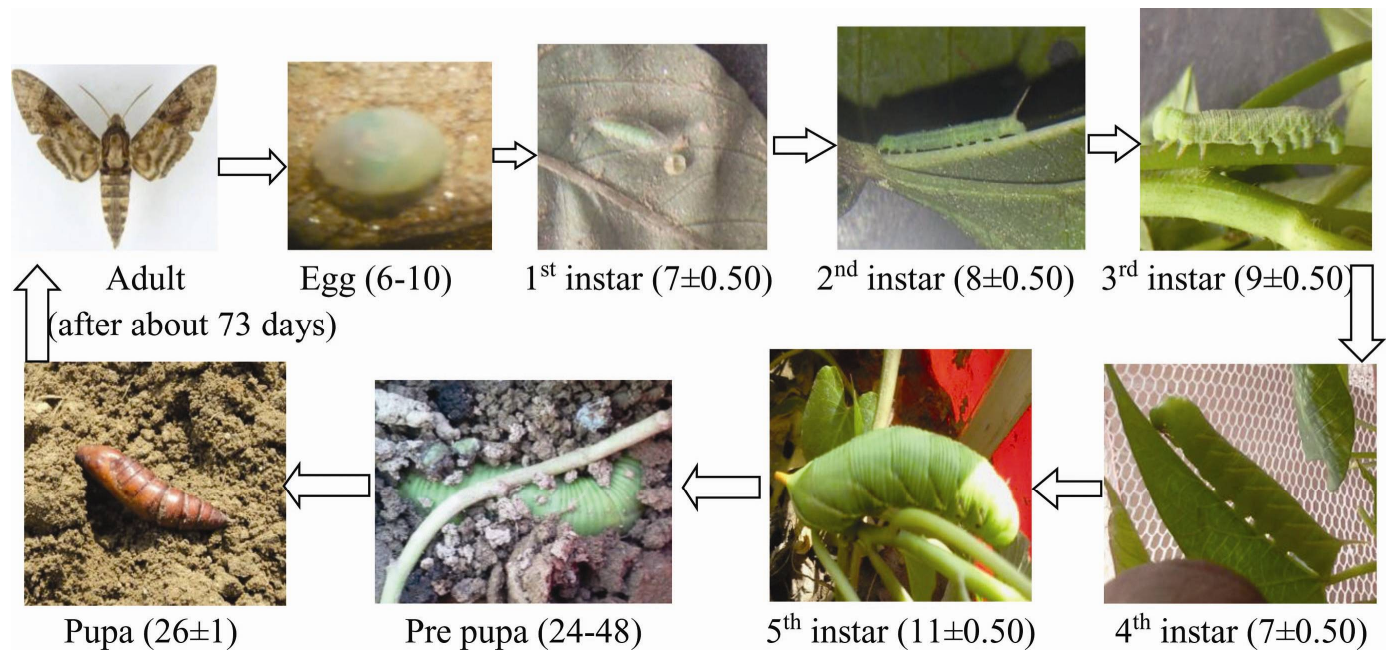

Fig. 3. Life cycle of Agrius cingulata (Time-duration in days).

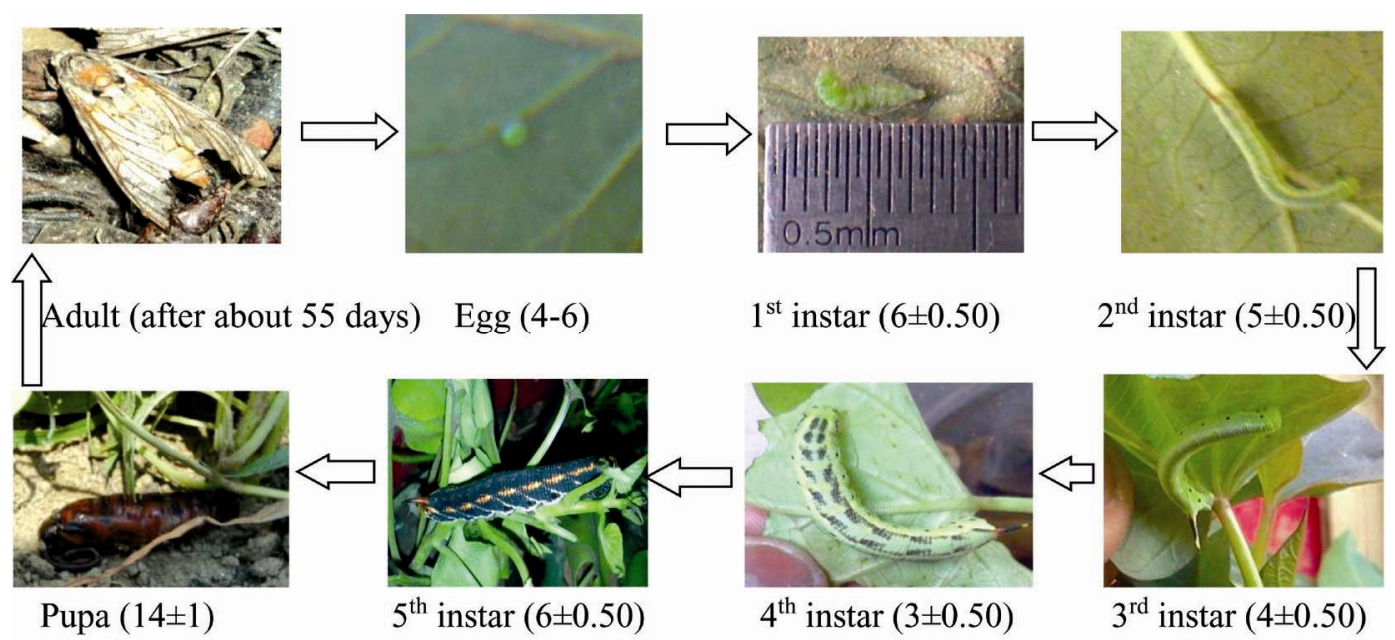

Fig. 4. Life cycle of Agrius convolvuli (Time-duration in days).

Fifth instar larval stage was the last stage of larval development of hawk moth. The whole body of $A$. cingulata became smooth, color of the body became yellowish-green, dark-brownish round markings on the body became most prominent. Finally, it became black which was covered by the white and deep black border (Fig. 3). On the other hand, in A. convolvuli yellowish and whitish stripes on the body covered from top to bottom; the pointed black marks were not identified individually because of their deep black 
body color (Fig. 4). But, the average duration of the 5th instar larva was ten to 12 days for A. cingulata and six days for $A$. convolvuli (Fig. 2).

In total, the average larval period was 46 - 48 days for $A$. cingulata and 26 - 28 days for A. convolvuli.

These findings on the larval morphology and larval developmental period were also observed by Bell and Scott(12), Kalshoven ${ }^{(13)}$ and Vasquez et al. ${ }^{(9)}$. According to Bell and Scott ${ }^{12}$, in the first instar, the head is small, the body long and thin ( $\left.3-4 \mathrm{~mm}\right)$, the horn straight with a bifid tip; head and body green, horn black. In the second instar there is little change. In the third instar, the head still small, the body increasing gradually in diameter from segment 2 to segment 8 , then nearly cylindrical; horn nearly vertical, thick at base, tapering evenly to a sharp point; surface of head and body smooth and shining. In the fourth instar there is little change. In the fifth instar, head round, horn reach to medium length, sharply down-curved, stout at base and tapering evenly to a sharp point. Surface of head and body was smooth and slightly shiny, the horn become smooth and polished. Vasquez et al.(9) found that a fully grown larva is $9 \mathrm{~cm}$ long. The larval period lasts 3 - 4 weeks. Pupation takes place in the soil in $5-26$ days, depending on the temperature. The larva of $A$. convolvuli grew faster than the larvae of $A$. cingulate, the larval duration was $42 \pm 1$ days for $A$. cingulata and $24 \pm 1$ days for $A$. convolvuli (Fig. 2).

The main difference in the morphology of $A$. cingulata and $A$. convolvuli larva was seen in the 2nd instar stage of hornworm and it became more conspicuous in the 4th to 5 th instar stage. In 5th instar stage they looked totally different.

Pre-pupal stage: At the end of the 5th larval instar, the body of the caterpillar gradually shrinked. The larvae ceased eating and wandered around for a pupation site. At the chosen site, the caterpillar prepared itself for undergoing pupation by making a chamber into the soil, under the host plant. Pre-pupal duration was 24 to $48 \mathrm{hrs}$.

Pupal stage: After one day of the pre-pupal stage, at maturity of the larva, pupation took place in the soil. The body surface was smooth, glossy, mahogany or leather brown, with a large, distinctive, 'jug-handle' proboscis. In $A$. cingulata, the duration of this stage was 20 - 30 days, and in A. convolvuli it was 5 - 26 days.

Adult: The adults were observed to emerge from the pupa by splitting and the pupal case vertically on the dorsal side, they were heavy bodied with long pointed front wings and short hind wings. The moth measured about $45 \mathrm{~mm}$ long and $90-100 \mathrm{~mm}$ in wingspan. The moths were often observed feeding flowers at dusk. The time taken for emergence was recorded $1-2 \mathrm{hrs}$.

A. convolvuli was dominant on $A$. cingulata. The significant difference was observed between the duration of incubation and larval period of $A$. cingulata and that of $A$. convolvuli. An average incubation period was $6 \pm 0.50$ days for A. cingulata and $4 \pm 0.50$ days for $A$. convolvuli, larval duration $42 \pm 1$ days for $A$. cingulata and $24 \pm 1$ days for $A$. convolvuli and pupal period $26 \pm 1$ days for $A$. cingulata and $14 \pm 1$ days for $A$. convolvuli. 
The total life cycle was 73 days for $A$. cingulata and 55 days for $A$. convolvuli, on an average.

The caterpillars of $A$. cingulata and A. convolvuli were found voracious feeder during the study period. The 1st instar larvae after hatching under the sweet potato leaf started feeding on the egg case. Almost all the larvae except a few made small holes with the help of their mouthparts. They defoliated mostly the very tender leaves by making small irregular shape holes. 1st and 2nd instar larvae sometimes used young leaves. The feeding time of the 1st and 2nd instar larvae was recorded 1-3 minutes followed by a resting period of $60-80$ minutes. For 3rd instar, the feeding time increased to $10-15$ minutes and resting period decreased to $40-50$ minutes. In case of 4 th and 5th instar larvae, the resting period was recorded 30 - 50 and 50 - 60 minutes, respectively and the feeding period was 20 - 35 and 30 - 40 minutes, respectively (Tables 1 and 2).

Table 1. Larval feeding potential of Agrius cingulata on different leaf maturity stages of Ipomoea batatas.

\begin{tabular}{|c|c|c|c|c|c|c|}
\hline \multirow{2}{*}{$\begin{array}{l}\text { Larval } \\
\text { instar }\end{array}$} & \multicolumn{4}{|c|}{ Leaf consumption in square $\mathrm{mm}$} & \multirow{2}{*}{$\begin{array}{l}\text { Feeding } \\
\text { time in } \\
\text { minute }\end{array}$} & \multirow{2}{*}{$\begin{array}{c}\text { Resting time } \\
\text { in } \\
\text { minute }\end{array}$} \\
\hline & Tender & Young & Mature & $\begin{array}{l}\text { Total consumed area } \\
\text { of leaves }\left(\mathrm{mm}^{2}\right)\end{array}$ & & \\
\hline 1st & 90 & 40 & 0 & 130 & 2 & 70 \\
\hline 2nd & 200 & 120 & 0 & 320 & 3 & 70 \\
\hline $3 \mathrm{rd}$ & 450 & 800 & 2500 & 3750 & 15 & 45 \\
\hline 4th & 60 & 2000 & 3000 & 5060 & 25 & 30 \\
\hline 5th & 70 & 4000 & 6500 & 10570 & 32 & 50 \\
\hline
\end{tabular}

Table 2. Larval feeding potential of Agrius convolvuli on different leaf maturity stages of Ipomoea batatas.

\begin{tabular}{|c|c|c|c|c|c|c|}
\hline \multirow{2}{*}{$\begin{array}{l}\text { Larval } \\
\text { instar }\end{array}$} & \multicolumn{4}{|c|}{ Leaf consumption in square $\mathrm{mm}$} & \multirow{2}{*}{$\begin{array}{l}\text { Feeding } \\
\text { time in } \\
\text { minute }\end{array}$} & \multirow{2}{*}{$\begin{array}{l}\text { Resting } \\
\text { time in } \\
\text { minute }\end{array}$} \\
\hline & Tender & Young & Mature & $\begin{array}{l}\text { Total consumed } \\
\text { area of leaves } \\
\left(\mathrm{mm}^{2}\right)\end{array}$ & & \\
\hline 1st & 60 & 40 & 0 & 100 & 2 & 70 \\
\hline 2nd & 120 & 120 & 0 & 240 & 4 & 70 \\
\hline $3 r d$ & 300 & 500 & 2000 & 2800 & 12 & 50 \\
\hline 4 th & 70 & 2500 & 2800 & 5370 & 20 & 42 \\
\hline 5th & 50 & 3000 & 6000 & 9050 & 28 & 60 \\
\hline
\end{tabular}


It was noticed during the study period that $A$. convolvuli was less voracious than $A$. cingulata. The resting period of $A$. convolvuli was higher than the feeding period, which was totally opposite to $A$. cingulata. The matured larvae were voracious feeder, which defoliated tender, young and mature leaves. In the absence of suitable leaves, the matured 3rd instar larvae were observed to feed on the tender shoots of the host plant, the robust 4th instar were found to consume the young, mature shoots, fruits etc. of the host plants and the 5th instar were found to consume the young, mature shoots, fruits, and also the androecium and gynoecium of the host plants (Fig. 5).

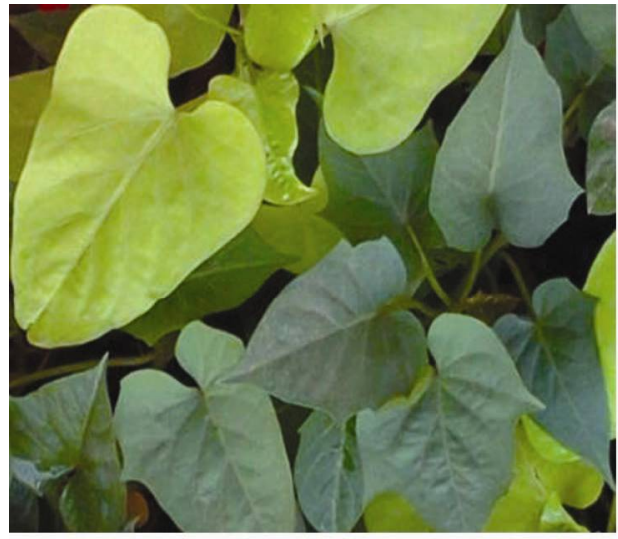

Before infestation

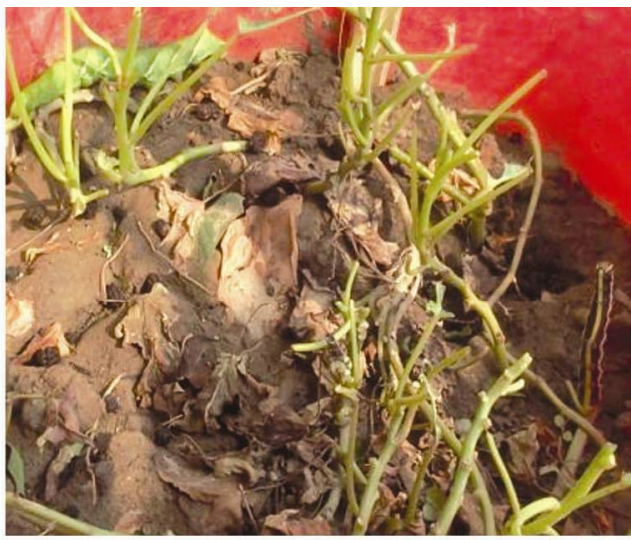

After infestation

Fig. 5. Nature of damage of sweet potato leaves by the larvae of hornworms.

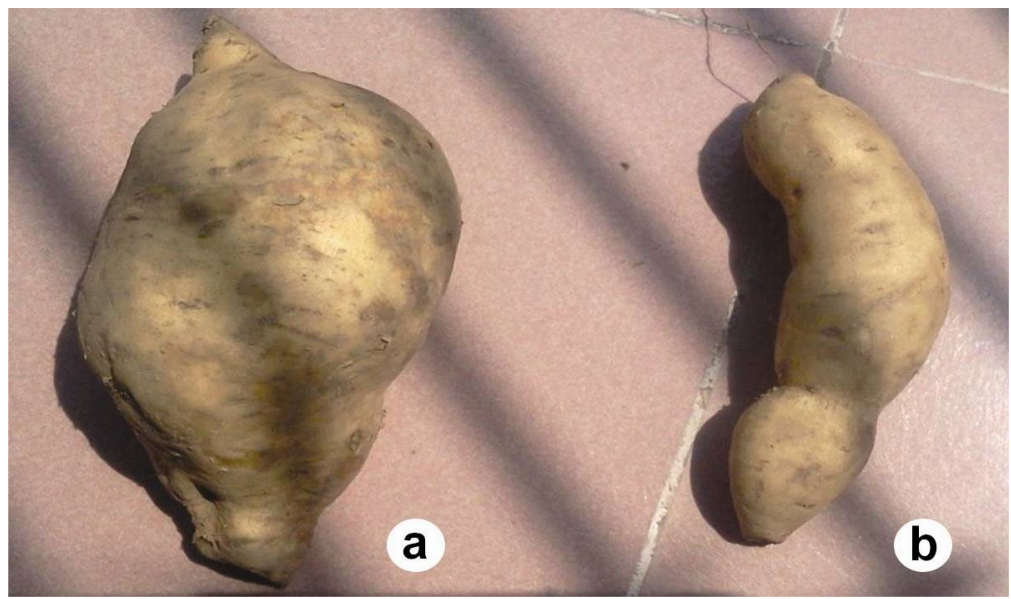

Fig. 6. Effect of infestation due to feeding of the sweet potato hornworm. (a) Sweet potato from non-infested plant; (b) Sweet potato from infested plant. 
The larvae stopped their feeding prior to molting. They selected the underside of mature leaves for pupation. The larval defoliation of sweet potato leaves causes indirect weight loss of sweet potatoes. According to Vasquez ${ }^{(9)}$, larvae of $A$. cingulata and $A$. convolvuli were found in sweet potato leaves. In the present study, it was also observed that, according to their feeding behavior $A$. cingulata and $A$. convolvuli were found only on leaf habitats. A. cingulata and $A$. convolvuli prefer the leaves for egg laying and consumption. They never attacked the sweet potato tuber directly. Approximately the total consumed areas of leaves were 19830 square $\mathrm{mm}$ for $A$. cingulata (Table 1) and 17560 square $\mathrm{mm}$ for $A$. convolvuli (Table 2) in their whole larval stage. Between the two pests it was obvious that, $A$. cingulata is more voracious and destructive pest than $A$. convolvuli.

The nature of damage of sweet potato horn worm mostly occurred on the host-plant. Larva was the only destructive stage of sweet potato hornworm which causes severe damage to the host-plant, the ultimate loss of sweet potato. Sweet potatoes were reduced in size and as a result their production was hampered (Fig. 6). The present study on the life cycle, feeding behavior and nature of damage of $A$. cingulata and A. convolvuli will be very useful for the control of the pests.

\section{References}

1. Vietmeyer ND 1986. Lesser known plants of potential use in agriculture and forestry. Sci. 232: 1379-1384.

2. Anonymous 1984. Annual Report of the Project "Root Crops Development in Bangladesh," 1983-84. Bangladesh Agri. Res. Inst., Joydebpur, Gazipur, Bangladesh. 58 pp.

3. Shonga E, M Gemu, T Tadesse and E Urage 2013. Review of Entomological Research on Sweet Potato in Ethiopia. J. Agric. Food Sci. 1(5): 15-22.

4. Adhanom N, A Tsedeke and G Emana 1985. Research on insect pests of root and tuber crops in Ethiopia. In: A review of crop protection research in Ethiopia. Institute of Agricultural Research, Ethiopia. pp. 423-431.

5. Ferdu A, M Baye, G Emana, A Temesgen, T Eyobe, G Mesele and W Biruk 2009. Review of Entomolological Research on Root and Tuber Crops in Ethiopia. PPSE and EIAR, Addis Ababa, Ethiopia. pp. 1- 46.

6. Talekar NS 1988. Insect pests of sweet potato in the tropics. In: Proceedings of the 11th International Congress on Crop Protection in the Tropic, Manila, October 1987, Bangkok, Thailand.

7. Pittaway AR 2005. Sphingidae of the Western Palearctic. Available on the internet, updated on 11. 02. 2006.

8. Lebot V 2009. Tropical Root and Tuber Crops: Cassava, Sweet Potato, Yams and Aroids. Wallingford, UK. 156 pp.

9. Vasquez EA and CE Sajise 1990. Pests of sweet potato: Insects, mites and diseases. Philippines Root Crop Information Service, Philippines Root Crop Research \& Training Center. 65 pp.

10. Pathak MD and ZR Khan 1994. Insect pests of rice. International Centre of Insect Physiology and Ecology, Nairobi, Kenya. 22 pp. 
11. Hodges RW 1971. The Moths of America North of Mexico, Fascicle 21 Sphingidae. E.W. Classey Ltd. \& R.B.D. Publications Inc. 170 pp.

12. Bell, TRD and FB Scott 1937. The Fauna of British India, including Ceylon and Burma, Moths. Volume V. (Sphingidae). London, xviii + 537 pp., 15 pls., 124 figs.

13. Kalshoven LGE 1981. Pest of crops in Indonesia. Revised and translated into English by P.A. van der Lann., P.T. Ichtiar Baru and Van Hoeve, Jakarta, Indonesia, 701 pp.

(Manuscript received on 3 January, 2018; revised on 8 April, 2018) 